\title{
1 Computer-delivered Cognitive Training and Transcranial Direct 2 Current Stimulation in Patients with HIV-associated Neurocognitive 3 Disorder: A Randomized Trial
}

4 Raymond L. Ownby ${ }^{*}$ and Jae Kim $^{1}$

$5{ }^{1}$ Department of Psychiatry and Behavioral Medicine, Nova Southeastern University, Fort Lauderdale,

6 Florida, USA

7 * Correspondence:

8 Dr. Ownby

9 ro71@nova.edu

10 Keywords: transcranial direct current stimulation, computer-delivered cognitive training, 11 human immunodeficiency virus, cognition, HIV-associated neurocognitive disorder, mild 12 neurocognitive disorder

\section{Abstract}

14 Objective: HIV infection is associated with impaired cognition, and as individuals grow older, they may also experience age-related changes in mental abilities. Previous studies have shown that computer-based cognitive training (CCT) and transcranial direct current stimulation (tDCS) may be useful in improving cognition in older persons. This study evaluated the acceptability of CCT and tDCS to older adults with HIV-associated neurocognitive disorder, and assessed their impact on reaction time, attention, and psychomotor speed.

Methods: In a single-blind randomized study, 46 individuals with HIV-associated mild neurocognitive disorder completed neuropsychological assessments and six 20-minute training sessions to which they had been randomly assigned to one of the following conditions: (1) CCT with active tDCS; (2) CCT with sham tDCS, or (3) watching educational videos with sham tDCS. Immediately after training and again one month later, participants completed follow-up assessments. Outcomes were evaluated via repeated measures mixed effects models.

Results: Participant ratings of the intervention were positive. Effects on reaction time were not significant, but measures of attention and psychomotor speed suggested positive effects of the intervention.

Conclusion: Both CCT and tDCS were highly acceptable to older persons with HIV infection. CCT and tDCS may improve cognitive in affected individuals.

31 Registered at ClinicalTrials.gov (NCT03440840).

\section{Introduction}

While there has been significant progress in the treatment of HIV infection using multiple antiretroviral medications, HIV-association neurocognitive disorders (HANDs) continue to be seen in affected individuals, even when their viral loads are nondetectable (Heaton et al., 2010). HANDs are clinically significant because of their impact on patients' everyday functioning [1-3], medication 
adherence $[1,4,5]$, and quality of life [6-9]. In older persons, HANDs may have an additive or even synergistic effect in older persons, combining the influences of chronic HIV infection and cognitive aging $[10,11]$.

Few treatments are available for HAND. Stimulants can improve cognition in HAND but may be abused by vulnerable individuals and have undesirable adverse effects [12]. Other medications treatments have been studied, but none has demonstrated clear efficacy [13-18]. Other researchers have suggested that computer-delivered cognitive training (CCT) may be useful in HAND [19-21], but specialized CCT software is not always readily available or affordable. Further, many programs created for CCT are not inherently interesting, reducing users' motivations for continued use after completing a study for which they were compensated. Another approach may be to use computer gaming software that is already available as a CCT intervention [22,23]. CCT software developers have sought to increase the inherent interest in their programs through gamification [24] to enhance their inherent interest, but many computer games are on the market now and often available at little or no cost. In addition, existing games depend on sustained use by players for their commercial success. Games such as these are interesting to players and include elements that engage them. Firstperson shooters (in which players use weapons to shoot at fictional enemies) can affect sustained attention and reaction time [24], however, some players may object to this type of game's violent content $[24,25]$.

Another established genre are games that provide players the simulated experience of car racing. These games require attention and psychomotor speed while using content that may be less objectionable. Use of one car racing game, created for a research study, was associated with better mental functioning in older persons [26]. Other researchers have commented on the possible usefulness of commercial computer games in addressing mental functioning in persons 50 years of age and older [23, 27-30]. Car racing games can engage and hold players' interest, potentially allowing them to continue cognitive training over extended periods. Researchers have shown that an off-the-shelf game that demanded mental speed resulted in longer use by older individuals when compared to a typical CCT program [29, 30]. Game play has been related to long-term mental training results, with effects evident in other cognitive domains besides those specifically trained [31]. Gaming has been shown, for example, to have a positive impact on the ability to regulate and direct mental processes [26]. Games may thus be effective for training and can engage users in a sustained fashion.

Transcranial direct current stimulation (tDCS) in combination with CCT has been shown to improve cognitive functioning [32-38]. tDCS is implemented by applying moistened sponge electrodes to a person's scalp and passing through a very small direct current (1-2 mA). tDCS research has shown that it can have a positive impact on various mental abilities, including verbal problem solving [39], working memory [40-42], and learning [43, 44].

How tDCS affects mental function is not definitively established, however, it has been shown to stimulate brain-derived neurotrophic growth factor (BDNF) in the motor cortex [45]. This may be especially relevant in treating persons with HAND as BDNF is affected in HIV infection [46, 47], and implicated in cognitive decline in older persons [48]. Increases in BDNF might be expected to exert a positive effect on mental functioning in persons with HAND.

We previously completed a pilot study of game-based CCT comparing its combination with active and sham tDCS in persons 50 years and older with HAND [49]. Results suggested that the intervention was acceptable to participants and that it may have had positive effects on their attention 
81

82

83

84

85

86

87

88

89

90

91

92

93

94

95

96

97

98

99

100

101

102

103

104

105

106

107

108

109

110

111

112

113

114

115

116

117

118

119

120

121

and working memory. In the follow-up study reported here, we further explore the acceptability and efficacy of a game-based CCT intervention combined with tDCS in older persons with HIV infection. We hypothesized that CCT with tDCS would be acceptable to persons 50 years of age and older with HAND. We also hypothesized that CCT would be associated with improved reaction time, psychomotor speed, and attention and that the combination of active tDCS with CCT would be superior to CCT alone.

\section{Methods}

\subsection{Participants}

Participants were individuals 50 years of age and older with HIV infection. Diagnosis of HAND was established through review of recent laboratory results, clinical evaluation, and neuropsychological testing. All participants stated they subjectively experienced cognitive difficulties and, after assessment, were found to have impairment of mental functioning in two or more cognitive domains while not having dementia, thus meeting Frascati criteria for mild neurocognitive disorder [15]. Potential participants were excluded if they had characteristics that might have increased risk to them from tDCS, such as seizures or bipolar disorder [50,51]. Use of many psychotropic medications was also an exclusion criterion, as the pharmacologic activity of many of these drugs can affect tDCS [52, 53]. Medications that were exclusions included those affecting serotonin, such as many antidepressants, dopamine, such as stimulants and antipsychotics, and gamma-amino butyric acid, such as benzodiazepines. Left-handed participants were excluded as our intent was to stimulate the dominant dorsolateral prefrontal cortex.

\subsection{Procedures}

\subsubsection{Recruitment and determination of eligibility}

Participants were first recruited from individuals who had been in a previous study. We also recruited from local service providers for persons with HIV. A number of participants referred friends or acquaintances. We distributed flyers in several areas of Broward County, Florida, known to have a high prevalence of HIV infection, as well as advertising in a local newspaper and creating a Facebook page.

Interested individuals were contacted for a telephone interview to establish that they had complaints of cognitive difficulties, using questions published by the European AIDS Clinical Society [54]. In this interview, we inquired about use of medications that might lead to exclusion, and whether the person was willing to be in a study of CCT and tDCS. All were being treated for HIV infection and had been on their current medication regimen for at least the past month. Individuals who, from this telephone interview, appeared likely to be eligible were asked to come to our offices for individual assessment.

At this assessment, potential participants completed a series of cognitive assessments (marked with an asterisk in Table 1). The battery was selected to allow evaluation of areas often affected in HANDs [55]. Attention and working memory were evaluated with the Digit Span subtests of the Wechsler Adult Intelligence Scale, 4th edition, or WAIS-IV [56]. Psychomotor speed was evaluated with the Coding subtest of the WAIS-IV and Grooved Pegboard Test [57]. Executive function was measured with the Trail Making Test, Part B [58]. Verbal fluency was assessed with the Verbal Fluency test of the Delis-Kaplan Executive Function System [59]. Verbal learning and memory were 
122

123

124

125

126

127

128

129

130

131

132

133

134

135

136

137

138

139

140

141

142

143

144

145

146

147

148

149

150

151

152

153

154

155

156

157

158

159

160

161

162

163 assessed with the Hopkins Verbal Learning Test—Revised or HVLT-R [60], and visual learning and memory with the Brief Visuospatial Memory Test, or BVMT-R [61].

Cognitive impairment for the purpose of establishing the diagnosis of mild neurocognitive disorder was defined as a score in at least two ability areas that was below population norms by at least one standard deviation. Participants were treated for HIV infection that included ongoing laboratory measures of treatment effects (HIV-1 viral load and CD4 cell counts). Individuals in the study brought recent laboratory results, allowing us to verify their HIV status and know their current treatment and immune status. All medications were also brought to this visit to allow verification of current medication use. Persons who met entry criteria then completed the additional assessments as described in the next section.

\subsubsection{Acceptability}

We used several strategies to evaluate the feasibility and acceptability of the CCT with tDCS intervention to participants. We used a questionnaire based on the Technology Acceptance Model, or TAM $[62,63]$, the dimensions of which have received substantial support for use with digital health technologies [64]. The model specifies that users' perceptions of an application's ease of use and usefulness are related to their future intention to use the application. We hypothesized that if the intervention were viewed favorably by participants, their average rating on the Usefulness and Ease of Use scales of this questionnaire would be significantly different from the midpoint of the scale in a positive direction.

Another scale was developed based on a model balancing risks and benefits of a treatment was used to develop a questionnaire assessing users' perceptions of the balance between an intervention's risks and benefits $[65,66]$. Participants were asked, for example, if they experienced benefits from the intervention and adverse effects from it. They were then asked to provide an overall judgment as to whether the benefits of the intervention outweighed its adverse effects.

\subsubsection{Cognitive measures}

In order to evaluate possible cognitive effects of the intervention more comprehensively, participants additional assessments after determination of their eligibility. Use of these measures allowed tests of the study's hypothesis that participants receiving the active interventions would display better performance than control participants in reaction time, attention, and psychomotor speed.

In order to evaluate intervention effects on participants' reaction time, they completed the California Computerized Assessment Package [67] (Miller, 2013). To further evaluate the effects of the intervention on executive functions, participants also completed the Stroop Color Word Test [68], the Iowa Gambling Task [69], and the Design Fluency subtest of the Delis-Kaplan Executive Function System [59](Delis et al., 2001). Finally, to assess whether the intervention had an impact on everyday functional performance, participants completed the Medication Management Test—Revised, a measure of the person's ability to understand and carry out medication-related tasks [70] and the University of San Diego Scales of Observed Performance [71], assessing their ability to perform everyday tasks such as making a medical appointment and paying a bill. Finally, in order to provide an estimate of participants' premorbid level of functioning, they completed the Wechsler Test of Adult Reading [72]. 


\subsubsection{Other self-report measures.}

166 The assessment battery also included the Patient's Assessment of Own Functioning or PAOF [73].

167 This measure asks the individual to self-report their experience of mental problems in several

168 domains such as language, perception, and memory. It has been used in other studies of HAND [74].

169 We also used the Center for Epidemiological Studies Depression scale or CESD [75] to assess participants' symptoms of depression. All self-report assessments were completed using computer software that read questions aloud and enabled participants to record their responses by tapping on the computer screen.

\section{$173 \quad 2.2 .5$ Compensation}

After these initial assessments were done, individuals in the study were asked to return to begin the intervention. Participants received compensation for their involvement, US $\$ 80$ for the baseline and follow-up sessions, and $\$ 40$ for each intervention visit.

\subsubsection{Computer-based cognitive training}

At the first training visit (after completion of baseline assessments), participants were assigned to intervention group using a computer-created randomization scheme. The scheme was generated via random numbers in a predetermined block $(n=3)$ randomization scheme. Participants were enrolled by the study coordinator (who was blind to treatment assignment) and assigned by the unblinded principal investigator who also conducted all training sessions.

183 First, procedures regarding the administration of tDCS and the use of the game controller (an Xbox 184 game controller with USB interface to a Windows computer). The participant sat in front of and to the right of the researcher; the participant could not see the direct current device for tDCS or the researcher taking notes during training. For all participants, the anode electrode was located over the left dorsolateral prefrontal cortex (10-20 system F3) and the cathode over the right supraorbital area (FP2) [76]. Soterix EASYPads, doubled sponges with dimensions of $5 \mathrm{~cm} \mathrm{x} 5 \mathrm{~cm}$ (Soterix Medical: New York) were used as electrodes. Approximately $7 \mathrm{cc}$ of sterile saline was used to moisten them. They were positioned by the researcher and then fixed in place with a head band. Current for the tDCS intervention was supplied with an iontophoresis device (ActivaDose II; Gilroy, CA: Activatek). Flat rubberized carbon electrodes were inserted into the moistened sponges. Impedances were assessed before each session and kept below $20 \mathrm{~K}$ ohms prior to stimulation.

We told people in the study that they might experience minor discomfort at the beginning of the session and that the experience might persist or fade away during the intervention [50]. We then asked the persons in the study to pay attention to the computer while the game was set up and the tDCS intervention was begun. Individuals in the active tDCS group received a current of $1.5 \mathrm{~mA}$, ramping up over $30 \mathrm{~s}$ and continuing for 20 minutes. Individuals in the sham tDCS group and the control group received the ramping up current for $30 \mathrm{~s}$ which was then ramped down over $30 \mathrm{~s}$.

The cognitive training intervention in this study was a commercially-available car racing game $G T$ and was positively reviewed by a large number of users. We inferred from these characteristics that the participants in the study would find the content tolerable and might even enjoy playing the game. The game includes a several different race courses and types of races to enhance player interest. 
206

207

208

209

210

211

212

213

214

215

216

217

218

219

220

221

222

223

224

225

226

227

228

229

230

231

232

233

234

235

236

237

238

239

240

241

242

243

244

245

246

Everyone in the study randomized to CCT was able to complete at least the first four courses during six training sessions.

We encouraged participants to complete each gaming session at their desired pace, although the game imposed some restrictions on their progress. Players had to finish each race in one of the top three places, or navigate a course within a predetermined time, before moving on to the next course. We required as well that participants do each course a minimum of five times. Persons in the study completed six training sessions over a two-week period. After each intervention session, participants were asked to provide ratings of their thinking, their mood, and how much discomfort they had experienced during the intervention.

Assessments and intervention sessions were completed within three weeks from the baseline evaluation. After participants finished the sixth intervention session, they returned to complete cognitive and self-report assessment. Cognitive evaluations were completed by staff who did not know the participant's intervention group assignment. About 30 days after completing the intervention sessions and follow-up evaluations, persons in the study were asked to return to again complete assessments. All data were collected in the General Clinical Research Center at the Center for Collaborative Research on the campus of Nova Southeastern University beginning in January 2018 and ending in November 2019. The study was concluded at the end of the period of funding support.

\subsection{Human subjects approval and trial registration}

Study procedures were approved by the Institutional Review Board of Nova Southeastern University (protocol number 2017-410). This study was registered on ClinicalTrials.gov (NCT03440840).

\subsection{Data Analyses}

Planned sample size was determined prior to beginning the study using the mixed effects model simulation routine in PASS 16 [77]. The power analysis showed that a final sample size of 90 (30 per treatment group) would have a power of 0.88 to detect interactions of group membership with time (number of evaluations) with a small effect size [78, 79].

Data analyses were completed in several steps. Preliminary analyses of data and descriptive statistics were obtained using SPSS version 26 (Armonk NY: IBM). Chi-square and one-way ANOVA tests evaluating the relations of participant ratings of the acceptability and feasibility of the intervention to group assignment were also completed in SPSS. Analyses of treatment effects were completed using $\mathrm{R}$ version 4.0.2 [80] package lme4 [81] for mixed effects models. Significance of model effects (interaction of treatment group assignment with time) was assessed using the likelihood ratio test [82]. We evaluated outcomes both through tests of statistical significance as well as approximations of effect size from $\chi^{2}$ values from likelihood ratio tests and $t$ values obtained in tests of betweengroup differences obtained using emmeans [83]. Effect sizes were converted to the more familiar d statistic using the package esc [84]. As a post-hoc assessment not included in the original study protocol the probability of finding the observed number of treatment effects in the hypothesized direction was evaluated using the exact binomial test in the package stats.

\section{Results}

The study's CONSORT diagram [85] is presented in Figure 1. Demographic, educational and baseline scores for cognitive and functional measures for participants by treatment group are 
presented in Table 2. We screened 155 potential participants, and included 46 in the study. Reasons for excluding potential participants are listed in Figure 1. The most frequent reasons for exclusion were use of psychotropic medications, and a personal or family history of bipolar disorder. We thus were not able to include the full number of participants in the study as originally envisioned (planned

$251 \mathrm{~N}=30$ per group).

252

253

254

255

256

257

258

259

260

261

262

\section{3}

264

265

266

267

268

269

270

271

272

273

274

275

276

\section{7}

278

279

280

281
Insert Figure 1 about here

Insert Table 2 about here

We explored relations of relevant covariates (age, gender, education, immune status) to mental ability variables with standard measures of association (correlations). As several of these associations were substantial and likely to create confounding relations, they were included as covariates in mixed effects random intercept models. Outcomes assessed were changes in test scores across treatment groups before and after the study intervention.

\subsection{Acceptability to participants}

As hypothesized, participants rated the intervention significantly more positively than the midpoint of the Usefulness subscale of the TAM scale. The mean rating for all participants was 4.33 (SD = 1.27; scale range 0 to 6$)$, and this rating was significantly greater than the neutral midpoint ( $\mathrm{t}[40]=$ $6.71, \mathrm{p}<0.001)$. We also found that they rated its ease of use positively with a mean rating of 5.04 $(\mathrm{SD}=0.95)$, ratings that were again significantly greater than the scale midpoint $(\mathrm{t}[43]=5.04, \mathrm{p}<$ 0.001). Ratings suggested that overall, they enjoyed the intervention (mean $=4.73 ; \mathrm{SD}=1.30$ ) and would use it again if given the opportunity (mean $=4.62 ; \mathrm{SD}=1.25)$. Participants' ratings did not vary by treatment group (all $p \mathrm{~s}>0.35$ ).

On the scale which asked participants to assess the intervention's risks and benefits, participant ratings again suggested a positive evaluation, with a mean rating of $4.53(\mathrm{SD}=1.20$; scale range 0 to $6)$ on the item "overall the good outweighs the bad" and a rating of $4.70(\mathrm{SD}=1.01)$ on the item "overall satisfaction." Forty-three of 46 participants (93\%) indicated they were satisfied with the intervention.

\subsection{Cognitive and functional outcomes}

Results of evaluations of study outcomes assessed as the interactions of intervention group across evaluations are available in Table 3. 
283

284

285

286

287

288

289

290

291

292

293

294

295

296

297

298

299

300

301

302

303

304

305

306

307

308

309

310

311

312

313

314

315

316

317
We found mixed evidence across cognitive domains to support the hypothesis that CCT with and without tDCS might result in improvements in cognitive functioning relative to control. For the Digit Span Forward subtest, the interaction of treatment group by time approached statistical significance and represented a large effect size. The difference between active tDCS and the control group (Figure 2) also approached statistical significance $(\mathrm{t}[61.3]=2.19, \mathrm{p}=0.08 ; \mathrm{d}=0.79)$. Other subtests hypothesized to assess attention showed similar positive but nonsignificant interactions.

Results did not support the hypothesis that persons receiving CCT with or without tDCS would show improved reaction time. Although the observed interactions were in the hypothesized direction, they were not significant and represented at best a very small effect size.

Results again provided limited support for the hypothesis that CCT with tDCS might result in improved psychomotor speed compared to control (Figure 3). Although the overall interaction of group by time was not significant for Trails $\mathrm{B}$, the comparison of the active treatment group to control approached significance ( $\mathrm{t}[67.2]=2.37, \mathrm{p}=0.053 ; \mathrm{d}=0.85)$, a difference that became significant at second follow-up $(\mathrm{t}[67.2]=3.03, \mathrm{p}=0.01 ; \mathrm{d}=1.09)$.

Insert Figure 2 about here

We found support for the hypothesis of improvement in psychomotor speed with a significant interaction of group by time for the WAIS-IV Coding subtest, although examination of the interaction plot suggests the effect was primarily due to the performance of persons in the CCT with sham tDCS (Figure 4). The between group difference from CCT + sham was not significant at immediate follow-up $(\mathrm{t}[45.6]=1.02, \mathrm{p}=0.57 ; \mathrm{d}=0.37)$ but approached significance at one-month follow-up $(\mathrm{t}[45.6]=2.21, \mathrm{p}=0.08 ; \mathrm{d}=0.79)$. 
Although we did not pose specific hypotheses for the effects of CCT with or without tDCS on executive function for this study, in exploratory analyses we evaluated the intervention's effects on this domain with several measures. A significant interaction of group by time was found for the Stroop with a large effect size, but as with several other measures, the finding was related to substantial improvement in the CCT with sham stimulation group. Other interactions were again positive but nonsignificant, with effect sizes in the moderate range.

As with executive function, we did not propose specific hypotheses for the two functional measures included in the assessments, but explored the intervention's effect on them. Results suggest a moderate but nonsignificant effect size for the MMT with a negligible effect size for the UPSA.

Given the large number of outcomes and our use of effect sizes to evaluate treatment effects, in an unplanned post-hoc analysis, we evaluated the overall impact of the study intervention based on the number of effect sizes for cognitive variables that were in the hypothesized direction (showing an interaction of group by time favoring one of the active treatment groups). The average effect size was 0.52 , with 17 effects equal to or greater than 0.16 , a small effect size [78]. The probability of this outcome compared to chance (equal distribution of positive effects across all groups) was significantly different $(\mathrm{p}=0.04)$. It is thus improbable that the observed effects of the intervention either treatment group and did not support the original hypothesis that the effects of CCT with active tDCS would be superior to CCT with sham tDCS.

\subsubsection{Self-report outcomes}

342 Evaluations of treatment by time interactions of participant self-report on the PAOF subscales (PAOF Memory, $\chi 2[4]=1.86, p=0.76, d=0.41$; Cognition subscale, $\chi^{2}[4]=0.37, p=0.98, d=$ $0.18)$ and the CESD $(\chi 2[4]=3.38, p=0.50, d=0.56)$ did not result suggest substantial betweengroup differences in response to the intervention. Examination of the interaction plots for the PAOF subscales (not presented) showed that mean scores for all three groups improved to a similar extent over the three evaluations. Participants reported similar levels of depression (CESD) across groups and evaluations, except participants in the active treatment group reported better mood at the onemonth follow-up evaluation. Although the test of between groups differences were not significant, the within-group change from the immediate follow-up to the one-month follow-up for the CCT with active $\mathrm{tDCS}$ group approached significance and represented a large effect size $(\mathrm{t}[78.2]=2.17, \mathrm{p}=$ $0.08, \mathrm{~d}=0.78)$.

353 Evaluation of participant ratings of how well they could think and remember resulted in an 354 interaction that again approached statistical significance $(\chi 2[10]=17.47, \mathrm{p}=0.06, \mathrm{~d}=1.59)$. reported better ability to think over the final three training sessions, although between-group differences were not statistically significant $(\mathrm{t}[106.8]=1.57, \mathrm{p}=0.26, \mathrm{~d}=0.56)$. 


\section{Discussion}

363 This study's goals were to assess the acceptability of CCT using a racing game to persons 50 years of age and older with HAND. The impact of adding tDCS to CCT was also evaluated. As we had a smaller than expected sample, we assessed outcomes not only through tests of statistical significance but also through calculation of effect sizes. Results showed that the majority of participants had positive views of the intervention and believed its benefits outweighed any risks. Ratings of its usefulness and usability were positive.

369 Our results clearly show that participants found the intervention acceptable. The majority of ratings 370 on factors such as usefulness and ease of use were positive, and nearly all participants indicated that they felt the benefits of the intervention outweighed any drawbacks. Further exploration of ways to make the intervention even more positive for persons with HAND appear warranted.

Assessment of mental abilities before and after training suggested that the intervention had a positive effect on learning, memory, and motor speed compared to control. Although only a few outcomes were statistically significant or approached it, those which were significant were associated with large effect sizes. Outcomes with moderate or smaller effect sizes may thus have been nonsignificant due to low power related to the sample size rather than a lack of effect. A post-hoc evaluation of the probability of arriving at the observed set of effect sizes by chance suggested that our findings were not due to chance. Further, effect sizes obtained in this study are similar to those reported by other researchers, including in a meta-analysis of studies with older adults [86].

Consistent with other research, the combination of cognitive training and anodal tDCS at the left dorsolateral prefrontal cortex was associated with improvement in attention as measured by digit span $[37,87,88]$. Contrary to our hypothesis, however, there was no evidence of a substantial impact of the intervention on reaction time. Others have reported that tDCS may have a facilitating effect on reaction time with anodal stimulation over primary motor cortex, but Molero-Chamizo et al. found that the effect was time dependent [89]. Others have also failed to find an effect of tDCS [90, 91] on reaction time. Our hypothesis of an effect on reaction time was based primarily on the nature of the training task (a fast-paced computer game), but neither statistical tests nor inspection of mean plots by groups (not presented) suggested an effect for either of the active treatment groups.

We found more substantial improvements in measures of psychomotor speed, including a significant interaction of group by time for the WAIS-IV Coding subtest. Although the overall interaction for Trails B was not significant, inspection of group mean plots was consistent with relatively greater improvement on this measure for the two active treatment groups, and post-hoc between groups tests showed a significant difference between the control and CCT + active tDCS group after treatment while none was found at baseline. 
left DLPFC disrupted Stroop performance [96], with the negative effect of cathodal vs anodal stimulation expected.

We found limited support for the impact of the intervention on functional measures, with a moderate effect size but nonsignificant results for the Medication Management Test but no evidence of an effect on the UPSA. This is similar results reported by Vance et al. [97] who found limited effects of cognitive training on various measures of everyday function.

Self-report measures of mood or subjective cognitive functioning did not differ between groups, with one exception. The failure to find group differences may have been related to self-reported improvements across all groups, including the control. The one exception were self-reports of how well the participant perceived their thinking and memory, for which the CCT + active tDCS group gave substantially more positive reports over the last several sessions of the intervention.

The finding of possible treatment effects later during the training period suggests that the intervention's effects may have continued after training ended, with continuing improvements at onemonth follow-up in psychomotor speed (Trail Making Test, Part B; Figure 3) and verbal learning (Hopkins Verbal Learning Test; Figure 5). We also found an improvement in depression self-report (Center for Epidemiological Studies - Depression) at one-month follow-up. This possibly delayed effect of tDCS on mood was also reported by Li [98]. Given the evidence for improvement during the second week of training, it is possible that a more intensive and longer intervention might have resulted in greater effects. This possibility should be explored in future studies.

Strengths of the study include the single-blind sham-controlled design, which was effective in our pilot study as it has been in other studies [99]. We collected all data using a staff member who did not know the participant's intervention assignment or by way of a computer. These measures reduced the likelihood of bias in outcomes due to experimenter effects. The characteristics of participants (age, gender, education level, cognitive function) made them similar to other persons who might have HAND and be able to benefit from the intervention. Another strength is the clear characterization of study participants with respect to concurrent medication use, although this in turn limited our ability to recruit participants.

This study's limitations include the smaller than planned sample size. In spite of intensive recruiting efforts in the local community, including newspaper and online advertising, multiple contacts with community organizations and local infectious disease practitioners, and contacts with participants in previous studies we were not able to recruit the planned number of participants for the study. As shown in Figure 1, we were able to contact a number of potential participants that might have been adequate for planned sample size for the study, but exclusion due to validity concerns related to psychotropic medication use and safety concerns related to history of bipolar disorder, a large number of potential participants were not eligible. This limitation in turn may have affected the ability to test the statistical significance of outcomes, although in several cases when we found large effect sizes, we also found statistically significant results. Generalizing our results based only on observed effect sizes is a limitation. Finally, it should be acknowledged that while we found a number of positive effects on cognitive measures in the two CCT groups, the original hypothesis that CCT with active tDCS would be superior to CCT with sham tDCS was not supported. 
441 As noted above, we did several things to reduce the possibility of effects related to the unblinded

442 experimenter. These included positioning the investigator and the tDCS device out of sight of the participant during stimulation, providing neutral suggestions about what the participants might experience during stimulation, and collecting most self-report data via computer assisted selfinterview with the investigators out of the room. All baseline and follow-up assessments were conducted by an assessor blind to the participant's treatment assignment or by way of a computer without the presence of a researcher. Thus, while we took a number of steps to reduce possible bias in the research design, they did not eliminate it.

449 HIV-related mental ability problems have implications for the functional status and quality of life for 450 older persons with HAND. Our results, though limited, demonstrate the possibility that CCT with or 451 without tDCS may have a positive impact on cognitive function. We found evidence of a moderate 452 though nonsignificant effect of the intervention on a test of medication taking, a critically important 453 skill for persons with HIV infection.

454 Future research should focus on continuing to explore the potential efficacy of CCT and tDCS with 455 this population. A more detailed exploration of factors such as intensity and duration of stimulation and length and frequency of training sessions as well as the optimal timing of follow-up assessments may yield more effective treatment protocols with greater impacts on participants' functional status.

\section{Conflict of Interest}

459 The authors declare that they have no known competing financial interests or personal relationships 460 that could have appeared to influence the work reported in this paper.

\section{Author Contributions}

462 RLO designed the study, obtained external funding, carried out the interventions, and wrote the draft of the manuscript. JK wrote a portion of the manuscript and reviewed the complete manuscript.

\section{$\begin{array}{lll}465 & 7 & \text { Funding }\end{array}$}

466 This work was supported by a grant from the US National Institutes on Aging to Dr. Ownby (grant 467 R21AG056256).

468

469 
References

472

473 1. Thames AD, Arentoft A, Rivera-Mindt M, Hinkin CH. Functional disability in medication management and driving among individuals with HIV: a 1-year follow-up study. J Clin Exp Neuropsychol. 2013;35(1):49-58.

2. Thames AD, Becker BW, Marcotte TD, Hines LJ, Foley JM, Ramezani A, et al. Depression, cognition, and self-appraisal of functional abilities in HIV: An examination of subjective appraisal aersus objective performance. The Clinical Neuropsychologist. 2011;25(2):224-43.

479 3. Thames AD, Kim MS, Becker BW, Foley JM, Hines LJ, Singer EJ, et al. Medication and 480 finance management among HIV-infected adults: The impact of age and cognition. Journal of 481 Clinical and Experimental Neuropsychology. 2011;33(2):200-9. adherence among HIV+ adults: effects of cognitive dysfunction and regimen complexity. Neurology. 2002;59(12):1944-50.

485 5. Hinkin CH, Hardy DJ, Mason KI, Castellon SA, Durvasula RS, Lam MN, et al. Medication adherence in HIV-infected adults: effect of patient age, cognitive status, and substance abuse. AIDS. 2004;18 Suppl 1:S19-25.

488 6. Degroote S, Vogelaers D, Vandijck DM. What determines health-related quality of life among people living with HIV: an updated review of the literature. Arch Public Health.

490 2014;72(1):40.

7. Degroote S, Vogelaers DP, Vermeir P, Mariman A, De RA, Van Der Gucht B, et al. Socioeconomic, behavioural, (neuro)psychological and clinical determinants of HRQoL in people living with HIV in Belgium: a pilot study. J Int AIDS Soc. 2013;16:18643.

494 8. Moore RC, Fazeli PL, Jeste DV, Moore DJ, Grant I, Woods SP. Successful cognitive aging 495 and health-related quality of life in younger and older adults infected with HIV. AIDS Behav. 496 2014;18(6):1186-97.

497 9. Tozzi V, Balestra P, Galgani S, Murri R, Bellagamba R, Narciso P, et al. Neurocognitive 498 performance and quality of life in patients with HIV infection. AIDS Res Hum Retroviruses.

$4992003 ; 19(8): 643-52$.

500 10. Valcour V, Shikuma C, Shiramizu B, Watters M, Poff P, Selnes O, et al. Higher frequency of dementia in older HIV-1 individuals: the Hawaii Aging with HIV-1 Cohort. Neurology.

503 11. Wendelken LA, Valcour V. Impact of HIV and aging on neuropsychological function. J 504 Neurovirol. 2012;18(4):256-63.

505 12. Hinkin CH, Castellon SA, Hardy DJ, Farinpour R, Newton T, Singer E. Methylphenidate 506 improves HIV-1-associated cognitive slowing. J Neuropsychiatry Clin Neurosci. 2001;13(2):248-54.

507 13. Decloedt EH, Freeman C, Howells F, Casson-Crook M, Lesosky M, Koutsilieri E, et al. 508 Moderate to severe HIV-associated neurocognitive impairment: A randomized placebo-controlled 509 trial of lithium. Medicine (Baltimore). 2016;95(46):e5401.

510 14. Nakasujja N, Miyahara S, Evans S, Lee A, Musisi S, Katabira E, et al. Randomized trial of 511 minocycline in the treatment of HIV-associated cognitive impairment. Neurology. 2013;80(2):196512202. 
513 15. Antinori A, Arendt G, Becker JT, Brew BJ, Byrd DA, Cherner M, et al. Updated research

514 nosology for HIV-associated neurocognitive disorders. Neurology. 2007;69(18):1789-99.

515 16. Sacktor N, Miyahara S, Deng L, Evans S, Schifitto G, Cohen BA, et al. Minocycline

516 treatment for HIV-associated cognitive impairment: results from a randomized trial. Neurology.

517 2011;77(12):1135-42.

518 17. Schifitto G, Yiannoutsos CT, Ernst T, Navia BA, Nath A, Sacktor N, et al. Selegiline and

519 oxidative stress in HIV-associated cognitive impairment. Neurology. 2009;73(23):1975-81.

520 18. Schifitto G, Zhang J, Evans SR, Sacktor N, Simpson D, Millar LL, et al. A multicenter trial of 521 selegiline transdermal system for HIV-associated cognitive impairment. Neurology.

522 2007;69(13):1314-21.

523 19. Cody SL, Vance DE. The neurobiology of HIV and its impact on cognitive reserve: A review 524 of cognitive interventions for an aging population. Neurobiol Dis. 2016;92(Pt B):144-56.

525 20. Vance DE, Fazeli PL, Cheatwood J, Nicholson WC, Morrison SA, Moneyham LD.

526 Computerized cognitive training for the neurocognitive complications of HIV infection: A systematic 527 review. J Assoc Nurses AIDS Care. 2019;30(1):51-72.

528 21. Vance DE, Fazeli PL, Ross LA, Wadley VG, Ball KK. Speed of processing training with 529 middle-age and older adults with HIV: a pilot study. J Assoc Nurses AIDS Care. 2012;23(6):500-10.

530 22. Bonnechère B, Langley C, Sahakian BJ. The use of commercial computerised cognitive 531 games in older adults: a meta-analysis. Scientific Reports. 2020;10(1):15276.

532 23. Zelinski EM, Reyes R. Cognitive benefits of computer games for older adults.

533 Gerontechnology. 2009;8(4):220-35.

534 24. Green CS, Seitz AR. The impacts of video games on cognition (and how the government can

535 guide the industry). Policy Insights from the Behavioral and Brain Sciences. 2015;2(1):101-10.

536 25. Wu S, Spence I. Playing shooter and driving videogames improves top-down guidance in 537 visual search. Atten Percept Psychophys. 2013;75(4):673-86.

538 26. Anguera JA, Boccanfuso J, Rintoul JL, Al-Hashimi O, Faraji F, Janowich J, et al. Video game 539 training enhances cognitive control in older adults. Nature. 2013;501(7465):97-101.

540 27. Basak C, Boot WR, Voss MW, Kramer AF. Can training in a real-time strategy video game 541 attenuate cognitive decline in older adults? Psychol Aging. 2008;23(4):765-77.

542 28. Bavelier D, Green CS. The brain-boosting power of video games. Sci Am. 2016;315(1):26-

54331.

544 29. Belchior P, Marsiske M, Leite WL, Yam A, Thomas K, Mann W. Older adults' engagement 545 during an intervention involving off-the-shelf videogame. Games Health J. 2016;5(3):151-6.

546 30. Belchior P, Marsiske M, Sisco S, Yam A, Mann W. Older adults' engagement with a video 547 game training program. Act Adapt Aging. 2012;36(4):269-79.

548 31. Cardoso-Leite P, Bavelier D. Video game play, attention, and learning: how to shape the 549 development of attention and influence learning? Curr Opin Neurol. 2014;27(2):185-91.

550 32. Coffman BA, Trumbo MC, Clark VP. Enhancement of object detection with transcranial

551 direct current stimulation is associated with increased attention. BMC Neurosci. 2012;13:108. 
552

553

554

555

556

557

558

559

560

561

562

563

564

565

566

567

568

569

570

571

572

573

574

575

576

577

578

579

580

581

582

583

584

585

586

587

588

589

590

591

592

593

594

33. Lawrence BJ, Gasson N, Bucks RS, Troeung L, Loftus AM. Cognitive training and noninvasive brain stimulation for cognition in Parkinson's disease: A meta-analysis. Neurorehabil Neural Repair. 2017;31(7):597-608.

34. Lawrence BJ, Gasson N, Johnson AR, Booth L, Loftus AM. Cognitive training and transcranial direct current stimulation for mild cognitive impairment in Parkinson's Disease: A randomized controlled trial. Parkinson's Disease. 2018;2018:4318475.

35. Leshikar ED, Leach RC, McCurdy MP, Trumbo MC, Sklenar AM, Frankenstein AN, et al. Transcranial direct current stimulation of dorsolateral prefrontal cortex during encoding improves recall but not recognition memory. Neuropsychologia. 2017;106:390-7.

36. Martin DM, Liu R, Alonzo A, Green M, Loo CK. Use of transcranial direct current stimulation (tDCS) to enhance cognitive training: effect of timing of stimulation. Exp Brain Res. 2014;232(10):3345-51.

37. Martin DM, Liu R, Alonzo A, Green M, Player MJ, Sachdev P, et al. Can transcranial direct current stimulation enhance outcomes from cognitive training? A randomized controlled trial in healthy participants. Int J Neuropsychopharmacol. 2013;16(9):1927-36.

38. Trumbo MC, Matzen LE, Coffman BA, Hunter MA, Jones AP, Robinson CSH, et al.

Enhanced working memory performance via transcranial direct current stimulation: The possibility of near and far transfer. Neuropsychologia. 2016;93(Pt A):85-96.

39. Cerruti C, Schlaug G. Anodal transcranial direct current stimulation of the prefrontal cortex enhances complex verbal associative thought. J Cogn Neurosci. 2009;21(10):1980-7.

40. Fregni F, Boggio PS, Nitsche M, Bermpohl F, Antal A, Feredoes E, et al. Anodal transcranial direct current stimulation of prefrontal cortex enhances working memory. Exp Brain Res. 2005;166(1):23-30.

41. Heimrath K, Sandmann P, Becke A, Muller NG, Zaehle T. Behavioral and electrophysiological effects of transcranial direct current stimulation of the parietal cortex in a visuospatial working memory task. Front Psychiatry. 2012;3:56.

42. Zaehle T, Sandmann P, Thorne JD, Jancke L, Herrmann CS. Transcranial direct current stimulation of the prefrontal cortex modulates working memory performance: combined behavioural and electrophysiological evidence. BMC Neurosci. 2011;12:2.

43. Clark VP, Coffman BA, Mayer AR, Weisend MP, Lane TD, Calhoun VD, et al. TDCS guided using fMRI significantly accelerates learning to identify concealed objects. Neuroimage. 2012;59(1):117-28.

44. Floel A, Suttorp W, Kohl O, Kurten J, Lohmann H, Breitenstein C, et al. Non-invasive brain stimulation improves object-location learning in the elderly. Neurobiol Aging. 2012;33(8):1682-9.

45. Fritsch B, Reis J, Martinowich K, Schambra HM, Ji Y, Cohen LG. Direct current stimulation promotes BDNF-dependent synaptic plasticity: potential implications for motor learning. Neuron. 2010;66.

46. Avdoshina V, Bachis A, Mocchetti I. Synaptic dysfunction in human immunodeficiency virus type-1-positive subjects: inflammation or impaired neuronal plasticity? J Intern Med. 2013;273(5):454-65.

47. Bachis A, Avdoshina V, Zecca L, Parsadanian M, Mocchetti I. Human immunodeficiency virus type 1 alters brain-derived neurotrophic factor processing in neurons. J Neurosci. 2012;32(28):9477-84. 
595

596

597

598

599

600

601

602

603

604

605

606

607

608

609

610

611

612

613

614

615

616

617

618

619

620

621

622

623

624

625

626

627

628

629

630

631

632

633

634

48. Buchman AS, Yu L, Boyle PA, Schneider JA, De Jager PL, Bennett DA. Higher brain BDNF gene expression is associated with slower cognitive decline in older adults. Neurology. 2016;86(8):735-41.

49. Ownby RL, Acevedo A. A pilot study of cognitive training with and without transcranial direct current stimulation (tDCS) to improve cognition in older persons with HIV-related cognitive impairment. Neuropsychiatr Dis Treat. 2016;12:2745-54.

50. Brunoni AR, Valiengo L, Baccaro A, Zanao TA, de Oliveira JF, Goulart A, et al. The sertraline vs. electrical current therapy for treating depression clinical study: results from a factorial, randomized, controlled trial. JAMA Psychiatry. 2013;70(4):383-91.

51. Galvez V, Alonzo A, Martin D, Mitchell PB, Sachdev P, Loo CK. Hypomania induction in a patient with bipolar II disorder by transcranial direct current stimulation (tDCS). J ECT. 2011;27(3):256-8.

52. McLaren ME, Nissim NR, Woods AJ. The effects of medication use in transcranial direct current stimulation: A brief review. Brain Stimulation: Basic, Translational, and Clinical Research in Neuromodulation. 2018;11(1):52-8.

53. Medeiros LF, de Souza IC, Vidor LP, de Souza A, Deitos A, Volz MS, et al. Neurobiological effects of transcranial direct current stimulation: A review. Frontiers in Psychiatry. 2012;3(110).

54. European AIDS Clinical Society. Guidelines 8.0. Brussels: European AIDS Clinical Society; 20152015.

55. Woods SP, Moore DJ, Weber E, Grant I. Cognitive neuropsychology of HIV-associated neurocognitive disorders. Neuropsychol Rev. 2009;19(2):152-68.

56. Wechsler D. Manual for the Wechsler Adult Intelligence Scale--IV. San Antonio TX: Pearson Assessment; 2008.

57. Lafayette Instrument Company. Grooved Pegboard Test user instructions. Lafayette IN: Lafayette Instrument Company; 2002.

58. Lezak M. Neuropsychological assessment, Fifth edition. New York: Oxford; 2004.

59. Delis DC, Kaplan E, Kramer JH. Delis-Kaplan Executive Function System (D-KEFS). San Antonio TX: The Psychological Corporation; 20012001.

60. Brandt J, Benedickt RH. Hopkins Verbal Learning Test--Revised: Professional manual. Odessa FL: Psychological Assessment Resources; 2001.

61. Benedict RB, Schretlen D, Groninger L, Dobraski M, Sphritz B. Revision of the Brief

Visuospatial Memory Test: Studies of normal performance, reliability and validity. Psychological Assessment. 1996;8:145-53.

62. Venkatesh V, Bala H. Technology Acceptance Model 3 and a research agenda on interventions. Decision Sciences. 2008;39(2):273-315.

63. Venkatesh V, Morris MG, Davis GB, Davis FD. User acceptance of information technology: Toward a unified view. MIS Quarterly. 2003;27(3):425-78.

64. Binyamin SS, Zafar BA. Proposing a mobile apps acceptance model for users in the health area: A systematic literature review and meta-analysis. Health Informatics Journal. 2021;27(1):1460458220976737. 
635 65. Atkinson MJ, Kumar R, Cappelleri JC, Hass SL. Hierarchical construct validity of the

636 treatment satisfaction questionnaire for medication (TSQM version II) among outpatient pharmacy

637 consumers. Value Health. 2005;8 Suppl 1:S9-S24.

638 66. Atkinson MJ, Sinha A, Hass SL, Colman SS, Kumar RN, Brod M, et al. Validation of a 639 general measure of treatment satisfaction, the Treatment Satisfaction Questionnaire for Medication 640 (TSQM), using a national panel study of chronic disease. Health Qual Life Outcomes. 2004;2:12.

641 67. Miller EN. California Computerized Assessment Package Manual, 2nd ed. Palm Springs, CA: 642 Eric N. Miller; 20132013.

643 68. Golden CJ. Stroop Color Word Test Manual. Chicago: Stoelting; 1978.

644 69. Bechara A, Damasio H, Tranel D, Damasio AR. The Iowa Gambling Task and the somatic 645 marker hypothesis: some questions and answers. Trends Cogn Sci. 2005;9(4):159-62; discussion 626464.

647 70. Albert SM, Weber CM, Todak G, Polanco C, Clouse R, McElhiney M, et al. An observed 648 performance test of medication management ability in HIV: Relation to neuropsychological status 649 and medication adherence outcomes. AIDS and Behavior. 1999;3(2):121-8.

650 71. Patterson TL, Goldman S, McKibbin CL, Hughs T, Jeste DV. UCSD Performance-Based 651 Skills Assessment: development of a new measure of everyday functioning for severely mentally ill 652 adults. Schizophr Bull. 2001;27(2):235-45.

653 72. Wechsler D. The Wechsler Test of Adult Reading. San Antonio: The Psychological 654 Corporation; 20012001.

655 73. Chelune GJ, Heaton RK, Lehman RAW. Neuropsychological and personality correlates of 656 patients' complaints of disability. In: Goldstein G, Tarter RE, editors. Advances in clinical 657 neuropsychology, Vol 3. New York: Springer; 1986. p. 95-126.

658 74. Rourke SB, Halman MH, Bassel C. Neurocognitive complaints in HIV-infection and their 659 relationship to depressive symptoms and neuropsychological functioning. J Clin Exp Neuropsychol. $660 \quad 1999 ; 21(6): 737-56$.

661 75. Radloff LS. The CES-D scale: A self-report depression scale for research in the general 662 population. Applied Psychological Measurement. 1977;1:385-481.

663 76. Acharya JN, Hani A, Cheek J, Thirumala P, Tsuchida TN. American Clinical

664 Neurophysiology Society guideline 2: Guidelines for standard electrode position nomenclature. J

665 Clin Neurophysiol. 2016;33(4):308-11.

666 77. Hintze J. PASS 16. Kaysville UT: NCSS, LLC.; 20182011.

667 78. Brydges CR. Effect size guidelines, sample size calculations, and statistical power in 668 gerontology. Innovation in Aging. 2019;3(4).

669 79. Cohen J. Statistical power analysis for the behavioral sciences (2nd ed.). New York:

$670 \quad$ Routledge; 1988.

671 80. R Core Team. R: A language and environment for statistical computing. Vienna, Austria: R 672 foundation for statistical computing; 2020.

673 81. Bates D, Maechler M, Bolker B, Walker S. Fitting linear mixed-effects models using lme4. 674 Journal of Statistical Software. 2015;67(1):1-48. 
82. Kuznetsova A, Brockhoff PB, Christensen RHB. ImerTest package: Tests in linear mixed

676 effects models. Journal of Statistical Software. 2017;82:1-26.

677 83. Lenth R. Estimated marginal means, aka least-squares means. 2020. p. R package version

678 1.5.0.

679 84. Ludecke D. Effect size computation for meta analysis. Vienna, Austria: R Core Team; 2019.

680 85. Moher D. CONSORT: an evolving tool to help improve the quality of reports of randomized

681 controlled trials. Consolidated Standards of Reporting Trials. Jama. 1998;279(18):1489-91.

682 86. Indahlastari A, Hardcastle C, Albizu A, Alvarez-Alvarado S, Boutzoukas EM, Evangelista

683 ND, et al. A systematic review and meta-analysis of transcranial direct current stimulation to

684 remediate age-related cognitive decline in healthy older adults. Neuropsychiatr Dis Treat.

685 2021;17:971-90.

686 87. Park S-H, Seo J-H, Kim Y-H, Ko M-H. Long-term effects of transcranial direct current

687 stimulation combined with computer-assisted cognitive training in healthy older adults. Neuroreport.

$6882014 ; 25$.

689 88. Santos VSdSd, Zortea M, Alves RL, Naziazeno CCdS, Saldanha JS, Carvalho SdCRd, et al.

690 Cognitive effects of transcranial direct current stimulation combined with working memory training

691 in fibromyalgia: a randomized clinical trial. Scientific Reports. 2018;8(1):12477.

692 89. Molero-Chamizo A, Alameda Bailén JR, Garrido Béjar T, García López M, Jaén Rodríguez I,

693 Gutiérrez Lérida C, et al. Poststimulation time interval-dependent effects of motor cortex anodal

694 tDCS on reaction-time task performance. Cogn Affect Behav Neurosci. 2018;18(1):167-75.

695 90. Coppens MJM, Staring WHA, Nonnekes J, Geurts ACH, Weerdesteyn V. Offline effects of

696 transcranial direct current stimulation on reaction times of lower extremity movements in people after

697 stroke: a pilot cross-over study. Journal of NeuroEngineering and Rehabilitation. 2019;16(1):136.

698 91. Seidel O, Ragert P. Effects of transcranial direct current stimulation of primary motor cortex

699 on reaction time and tapping performance: A comparison between athletes and non-athletes. Frontiers

700 in Human Neuroscience. 2019;13(103).

701 92. Scarpina F, Tagini S. The Stroop Color and Word Test. Frontiers in Psychology. 2017;8(557).

702 93. Loftus AM, Yalcin O, Baughman FD, Vanman EJ, Hagger MS. The impact of transcranial

703 direct current stimulation on inhibitory control in young adults. Brain Behav. 2015;5(5):e00332.

704 94. Lu H, Gong Y, Huang P, Zhang Y, Guo Z, Zhu X, et al. Effect of repeated anodal HD-tDCS

705 on executive functions: Evidence from a pilot and single-blinded fNIRS study. Frontiers in Human

706 Neuroscience. 2021;14(609).

707 95. Perrotta D, Bianco V, Berchicci M, Quinzi F, Perri RL. Anodal tDCS over the dorsolateral

708 prefrontal cortex reduces Stroop errors. A comparison of different tasks and designs. Behavioural

709 Brain Research. 2021;405:113215.

710 96. Frings C, Brinkmann T, Friehs MA, van Lipzig T. Single session tDCS over the left DLPFC

711 disrupts interference processing. Brain Cogn. 2018;120:1-7.

712 97. Vance DE, Fazeli P, Azuero A, Frank JS, Wadley VG, Raper JL, et al. Can individualized-

713 targeted computerized cognitive training improve everyday functioning in adults with HIV-

714 associated neurocognitive disorder? Applied Neuropsychology: Adult. 2021:1-12. 
medRxiv preprint doi: https://doi.org/10.1101/2021.08.22.21262416; this version posted September 24, 2021. The copyright holder for this preprint (which was not certified by peer review) is the author/funder, who has granted medRxiv a license to display the preprint in perpetuity. It is made available under a CC-BY-NC-ND 4.0 International licens C.CT and tDCS for HAND

$71598 . \quad$ Li M-S, Du X-D, Chu H-C, Liao Y-Y, Pan W, Li Z, et al. Delayed effect of bifrontal

716 transcranial direct current stimulation in patients with treatment-resistant depression: a pilot study.

717 BMC Psychiatry. 2019;19(1):180.

718 99. Woods AJ, Antal A, Bikson M, Boggio PS, Brunoni AR, Celnik P, et al. A technical guide to 719 tDCS, and related non-invasive brain stimulation tools. Clin Neurophysiol. 2016;127(2):1031-48.

720

721 
medRxiv preprint doi: https://doi.org/10.1101/2021.08.22.21262416; this version posted September 24, 2021. The copyright holder for this preprint (which was not certified by peer review) is the author/funder, who has granted medRxiv a license to display the preprint in perpetuity. It is made available under a CC-BY-NC-ND 4.0 Grognitive |teajning and tDCS for HAND

\section{$\begin{array}{lll}722 & 8 & \text { Figure Captions }\end{array}$}

723 Figure 1. CONSORT diagram

724 Figure 2. WAIS-IV Digit Span Forward subtest score by Group and Time

725 Figure 3. Trail Making Test, Part B by Group and Time

726 Figure 3 footnote: Lower scores indicate better performance

727 Figure 4. WAIS-IV Coding subtest scores by Group and Time

728 Figure 5. Hopkins Verbal Learning Test total score, Part B by Group and Time

729 Figure 6. Participants' Self-rated Thinking and Memory by Group and Training Session 730 
medRxiv preprint doi: https://doi.org/10.1101/2021.08.22.21262416; this version posted September 24, 2021. The copyright holder for this preprint (which was not certified by peer review) is the author/funder, who has granted medRxiv a license to display the preprint in perpetuity.

Table 1. Cognitive and Functional Measures Used

\begin{tabular}{|c|c|}
\hline Domain & Measure \\
\hline Reaction Time & California Computerized Assessment Package (CalCap) [66] \\
\hline \multirow[t]{2}{*}{ Attention } & ${ }^{*}$ Wechsler Adult Intelligence Scale, $4^{\text {th }}$ Ed., Digit Span subtest [99] \\
\hline & Wechsler Memory Scale, $4^{\text {th }}$ ed., Symbol Span subtest [101] \\
\hline \multirow[t]{3}{*}{$\begin{array}{l}\text { Psychomotor } \\
\text { Speed }\end{array}$} & ${ }^{*}$ Wechsler Adult Intelligence Scale, $4^{\text {th }}$ ed., Coding subtest [100] \\
\hline & *Trail Making Test, Part A [78] \\
\hline & *Grooved Pegboard [51] \\
\hline Premorbid function & Wechsler Test of Adult Reading [98] \\
\hline \multirow[t]{4}{*}{ Executive function } & ${ }^{*}$ Trail Making Test, Part B [78] \\
\hline & *Verbal and Design Fluency from D-KEFS [36] \\
\hline & Stroop Color Word Test [42] \\
\hline & lowa Gambling Task [12] \\
\hline \multirow[t]{2}{*}{$\begin{array}{l}\text { Learning and } \\
\text { Memory }\end{array}$} & *Hopkins Verbal Learning Test - Revised [15] \\
\hline & ${ }^{*}$ Brief Visuospatial Memory Test - Revised [16] \\
\hline \multirow[t]{2}{*}{ Functional Status } & Medication Management Test - Revised [2] \\
\hline & $\begin{array}{l}\text { University of California San Diego Performance-based Skills } \\
\text { Assessment }[74,70]\end{array}$ \\
\hline
\end{tabular}


medRxiv preprint doi: https://doi.org/10.1101/2021.08.22.21262416; this version posted September 24, 2021. The copyright holder for this preprint (which was not certified by peer review) is the author/funder, who has granted medRxiv a license to display the preprint in perpetuity.

It is made available under a CC-BY-NC-ND 4.0 Grgnitike liteajeing and tDCS for HAND

Table 2. Baseline characteristics of treatment groups

\begin{tabular}{|c|c|c|c|c|c|c|}
\hline \multirow{4}{*}{$\begin{array}{l}\text { Gender } \\
\text { Race }\end{array}$} & \multicolumn{2}{|c|}{$\begin{array}{c}\text { Active + CT } \\
(n=16)\end{array}$} & \multicolumn{2}{|c|}{$\begin{array}{c}\text { Sham + CT } \\
(n=15)\end{array}$} & \multicolumn{2}{|c|}{ Control $(n=15)$} \\
\hline & \multicolumn{2}{|c|}{13 Men, 3 Women } & \multicolumn{2}{|c|}{13 Men, 2 Women } & \multicolumn{2}{|c|}{11 Men, 4 Women } \\
\hline & \multicolumn{2}{|c|}{5 White, 11 Black } & \multicolumn{2}{|c|}{7 White, 8 Black } & \multicolumn{2}{|c|}{5 White, 10 Black } \\
\hline & Mean & SD & Mean & SD & Mean & SD \\
\hline Age (years) & 57.06 & 4.99 & 58.80 & 4.13 & 61.07 & 6.28 \\
\hline Education (years) & 11.94 & 3.45 & 14.00 & 3.59 & 13.33 & 3.39 \\
\hline WTAR VIQ ${ }^{a}$ & 96.75 & 14.56 & 102.40 & 16.10 & 95.93 & 14.84 \\
\hline WAIS-IV Forward ${ }^{\mathrm{b}}$ & 8.31 & 1.66 & 9.67 & 2.13 & 8.27 & 2.22 \\
\hline WAIS-IV Backward & 6.56 & 1.55 & 7.53 & 2.75 & 7.00 & 1.93 \\
\hline WAIS-IV Sequence & 7.44 & 1.97 & 7.73 & 2.69 & 6.93 & 1.98 \\
\hline WAIS-IV Total & 22.31 & 3.96 & 24.93 & 6.75 & 22.2 & 4.92 \\
\hline $\begin{array}{l}\text { WMS-IV Symbol } \\
\text { Span }\end{array}$ & 16.13 & 5.10 & 16.07 & 7.42 & 12.53 & 4.05 \\
\hline $\begin{array}{l}\text { Simple Reaction } \\
\text { Time (ms) }\end{array}$ & 638.31 & 123.37 & 620.87 & 127.66 & 653.84 & 122.89 \\
\hline $\begin{array}{l}\text { Choice Reaction } \\
\text { Time (ms) }\end{array}$ & 538.63 & 99.33 & 523.33 & 90.75 & 542.64 & 122.29 \\
\hline HVLT Total & 21.69 & 3.16 & 20.40 & 5.90 & 19.53 & 3.83 \\
\hline HVLT Delayed & 6.81 & 2.56 & 6.47 & 2.48 & 5.60 & 2.50 \\
\hline BVMT Total & 14.50 & 4.66 & 15.13 & 8.63 & 11.80 & 6.93 \\
\hline BVMT Delayed & 6.38 & 2.78 & 6.40 & 3.46 & 4.53 & 3.44 \\
\hline Trails A & 42.81 & 16.37 & 43.93 & 20.10 & 46.20 & 11.01 \\
\hline Trails B & 98.88 & 33.40 & 117.53 & 40.20 & 117.73 & 37.45 \\
\hline Pegs R & 99.50 & 22.96 & 94.73 & 21.35 & 101.47 & 23.05 \\
\hline WAIS-IV Coding & 48.94 & 9.28 & 51.67 & 13.70 & 46.07 & 15.52 \\
\hline Stroop & 29.69 & 6.98 & 32.27 & 9.66 & 24.80 & 9.87 \\
\hline IGT & -6.67 & 22.84 & 7.73 & 26.70 & -4.67 & 29.51 \\
\hline MMT & 11.94 & 2.59 & 13.53 & 3.56 & 11.53 & 4.53 \\
\hline UPSA & 79.75 & 10.71 & 80.20 & 16.40 & 76.73 & 13.72 \\
\hline
\end{tabular}

733 'WTAR VIQ = Wechsler Test of Adult Reading estimated verbal IQ;

734 'bAIS-IV Forward = Wechsler Adult Intelligence Scale, $4^{\text {th }}$ Ed (WAIS-IV) Digit Span

735 Forward subtest; WAIS-IV Backward = WAIS-IV Digit Span Backward subtest; WAIS-IV

736 Sequence = WAIS-IV Sequencing subtest; WAIS-IV Total = WAIS-IV Digit Span total of 
737 three subtests; WMS-IV Symbol $=$ Wechsler Memory Scale, $4^{\text {th }}$ ed, Symbol Span subtest;

738 Simple Reaction Time = California Computerized Assessment Package Simple Reaction

739 task; Choice Reaction Time = California Computerized Assessment Package Choice

740 Reaction task; HVLT Total = Hopkins Verbal Learning Test total score; HVLT Delayed =

741 Hopkins Verbal Learning Test delayed recall score; BVMT Total = Brief Visuospatial

742 Memory Test--Revised total score; BVMT Delayed = Brief Visuospatial Memory Test--

743 Revised delayed recall score; Trails $A=$ Trail Making Test, Part A; Trails B = Trail Making

744 Test, Part B; Pegs $\mathrm{R}=$ Grooved Pegboard, right hand performance; WAIS-IV Coding =

745 WAIS-IV Coding subtest; Stroop = Stroop Color-Word test score; IGT = lowa Gambling

746 Task Net Total score; Verbal Fluency = DKEFS Category Fluency subtest; Design Fluence

747 = DKEFS Design Fluency subtest; MMT = Medication Management Test-Revised score;

748 UPSA Total = UCSD Performance-Based Skills Assessment; subtest. 
medRxiv preprint doi: https://doi.org/10.1101/2021.08.22.21262416; this version posted September 24, 2021. The copyright holder for this preprint (which was not certified by peer review) is the author/funder, who has granted medRxiv a license to display the preprint in perpetuity.

Table 3. Likelihood ratio test and effect sizes for the interaction of group by time

\begin{tabular}{|c|c|c|c|c|}
\hline & $x^{2}$ & df & $p$ & $d$ \\
\hline WAIS-IV Forward ${ }^{a}$ & 9.03 & 4 & 0.06 & 0.99 \\
\hline WAIS-IV Backward & 2.56 & 4 & 0.82 & 0.38 \\
\hline WAIS-IV Sequence & 4.06 & 4 & 0.40 & 0.62 \\
\hline WAIS-IV Total & 6.55 & 4 & 0.16 & 0.82 \\
\hline WMS-IV Symbol Span & 2.79 & 4 & 0.59 & 0.51 \\
\hline Simple Reaction Time & 0.19 & 4 & 0.66 & 0.13 \\
\hline Choice Reaction Time & 0.29 & 4 & 0.59 & 0.16 \\
\hline Trails A & 1.14 & 4 & 0.89 & 0.32 \\
\hline Trails B & 3.85 & 4 & 0.43 & 0.60 \\
\hline Pegs $R^{b}$ & 4.54 & 4 & 0.34 & $(0.66)$ \\
\hline WAIS-IV Coding & 11.80 & 4 & 0.02 & 1.17 \\
\hline HVLT Total & 4.37 & 4 & 0.36 & 0.65 \\
\hline HVLT Delayed & 2.13 & 4 & 0.71 & 0.44 \\
\hline BVMT Total (note) & 6.86 & 4 & 0.14 & 0.84 \\
\hline BVMT Delayed & 0.81 & 4 & 0.94 & 0.27 \\
\hline Stroop & 9.64 & 4 & 0.046 & 1.03 \\
\hline IGT Net Total & 5.34 & 4 & 0.25 & 0.73 \\
\hline Verbal Fluency & 5.84 & 4 & 0.21 & 0.76 \\
\hline Design Fluency & 5.94 & 4 & 0.20 & 0.77 \\
\hline MMT & 2.30 & 4 & 0.68 & 0.46 \\
\hline UPSA Total & 2.40 & 4 & 0.66 & 0.02 \\
\hline
\end{tabular}

${ }^{a}$ WAIS-IV Forward $=$ Wechsler Adult Intelligence Scale, $4^{\text {th }}$ Ed (WAIS-IV) Digit Span

751 Forward subtest; WAIS-IV Backward = WAIS-IV Digit Span Backward subtest; WAIS-IV

752 Sequence = WAIS-IV Sequencing subtest; WAIS-IV Total = WAIS-IV Digit Span total of

753 three subtests; WMS-IV Symbol = Wechsler Memory Scale, $4^{\text {th }}$ ed, Symbol Span subtest;

754 Simple Reaction Time = California Computerized Assessment Package Simple Reaction 
medRxiv preprint doi: https://doi.org/10.1101/2021.08.22.21262416; this version posted September 24, 2021. The copyright holder for this preprint (which was not certified by peer review) is the author/funder, who has granted medRxiv a license to display the preprint in perpetuity.

755 task; Choice Reaction Time $=$ California Computerized Assessment Package Choice

756 Reaction task; HVLT Total $=$ Hopkins Verbal Learning Test total score; HVLT Delayed =

757 Hopkins Verbal Learning Test delayed recall score; BVMT Total = Brief Visuospatial

758 Memory Test--Revised total score; BVMT Delayed = Brief Visuospatial Memory Test--

759 Revised delayed recall score; Trails $A=$ Trail Making Test, Part A; Trails $B=$ Trail Making

760 Test, Part B; Pegs $\mathrm{R}=$ Grooved Pegboard, right hand performance; WAIS-IV Coding =

761 WAIS-IV Coding subtest; Stroop = Stroop Color-Word test score; IGT = lowa Gambling

762 Task Net Total score; Verbal Fluency = DKEFS Category Fluency subtest; Design Fluence

763 = DKEFS Design Fluency subtest; MMT = Medication Management Test-Revised score;

764 UPSA Total = UCSD Performance-Based Skills Assessment; subtest. 


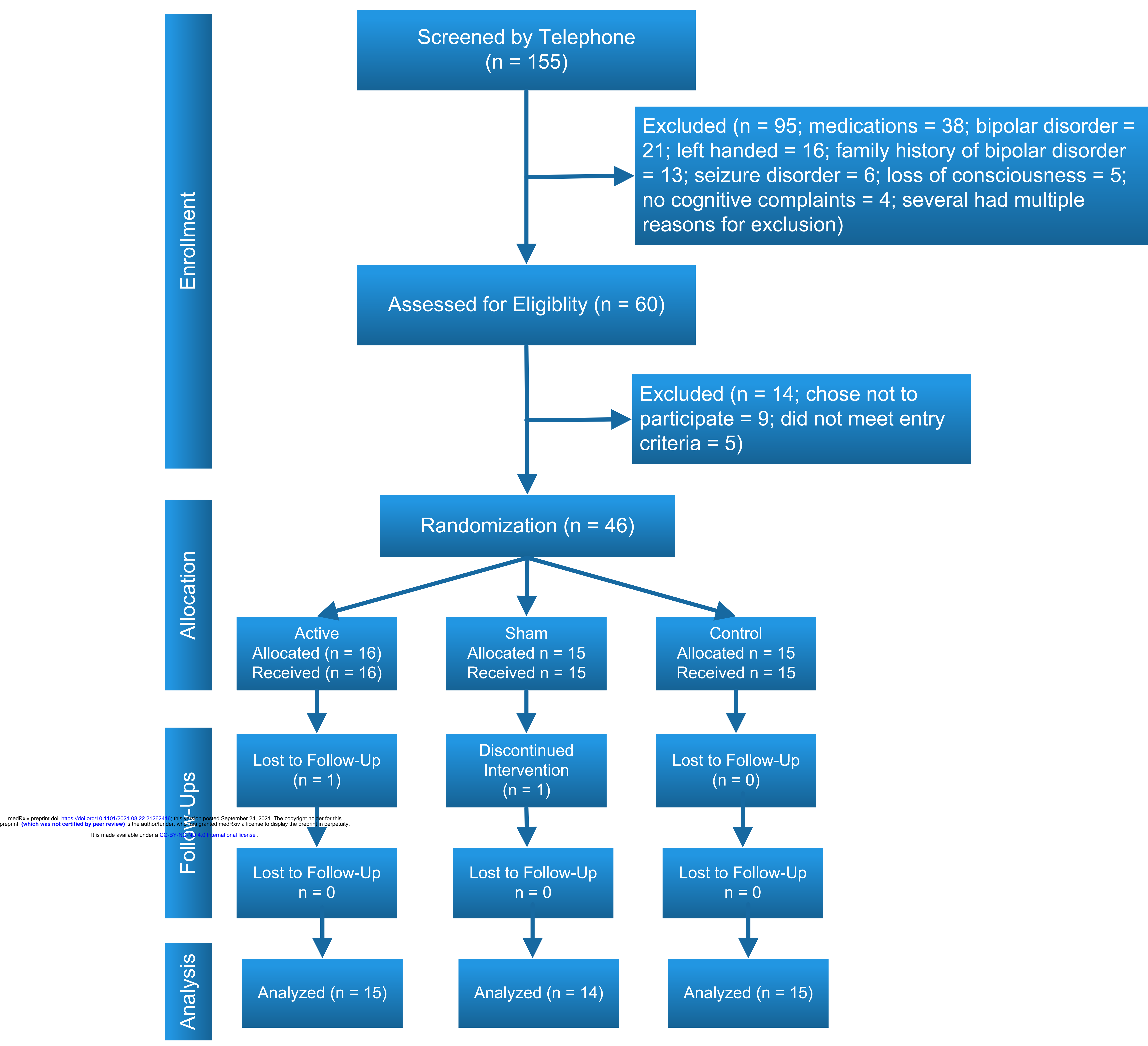









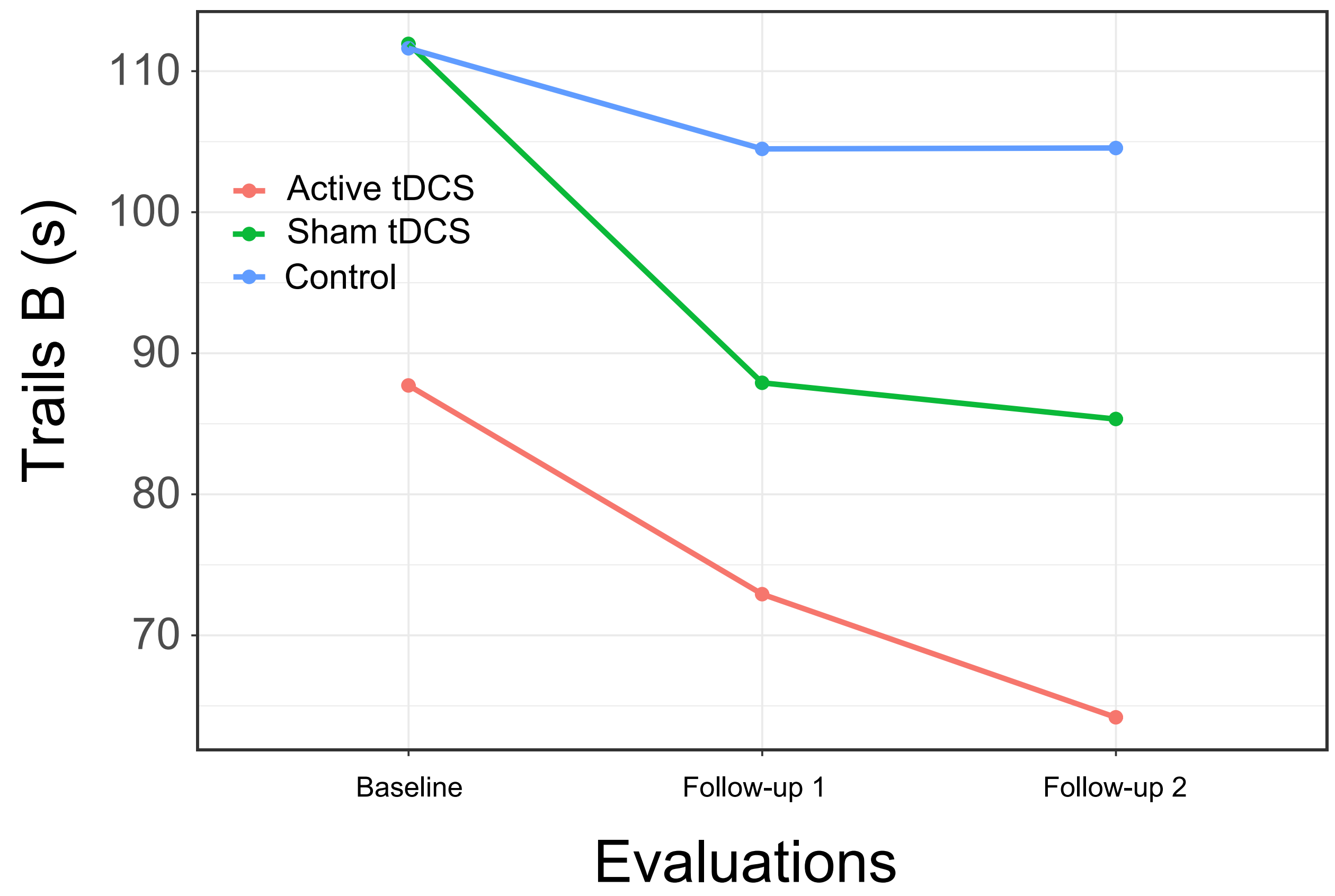




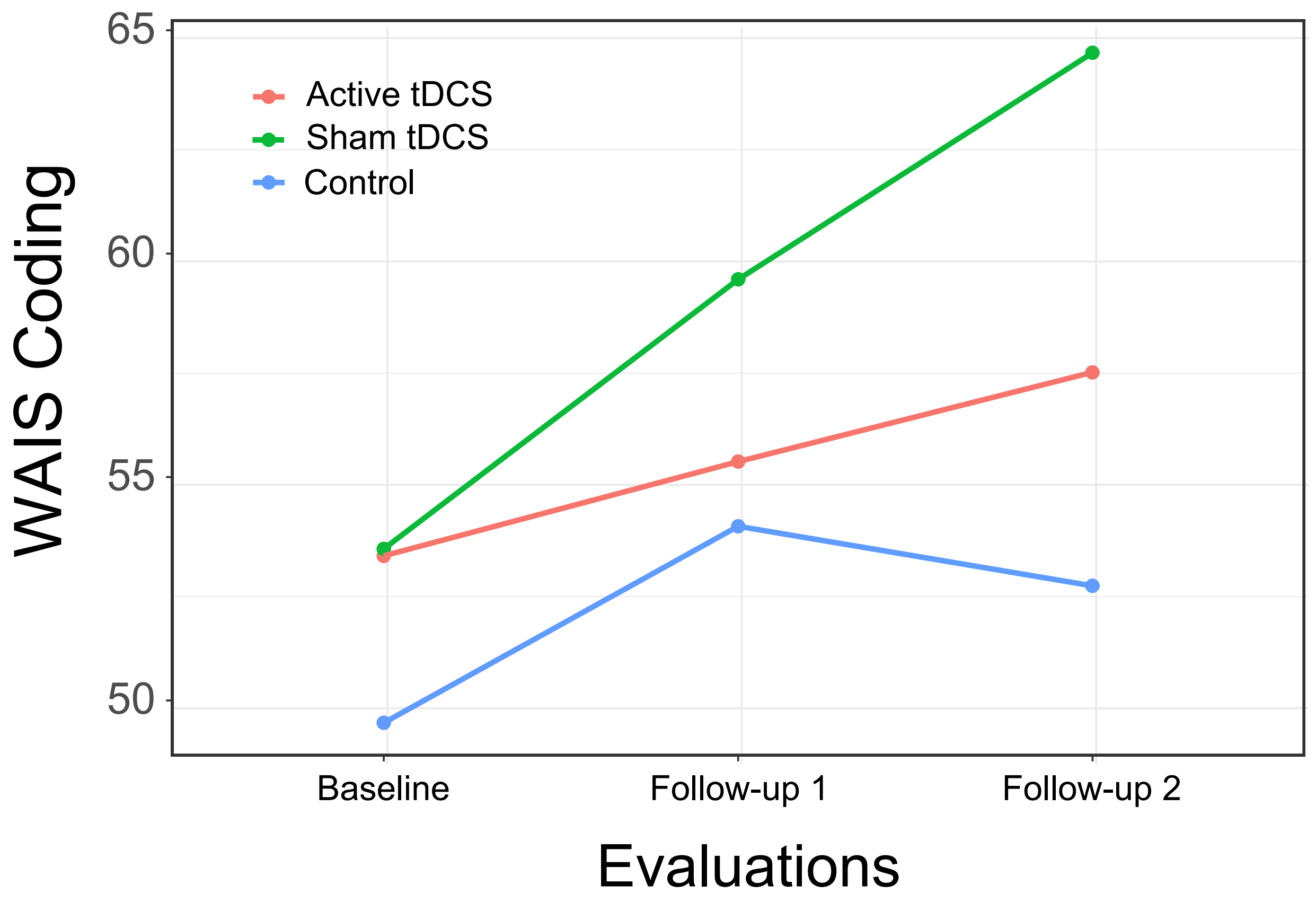




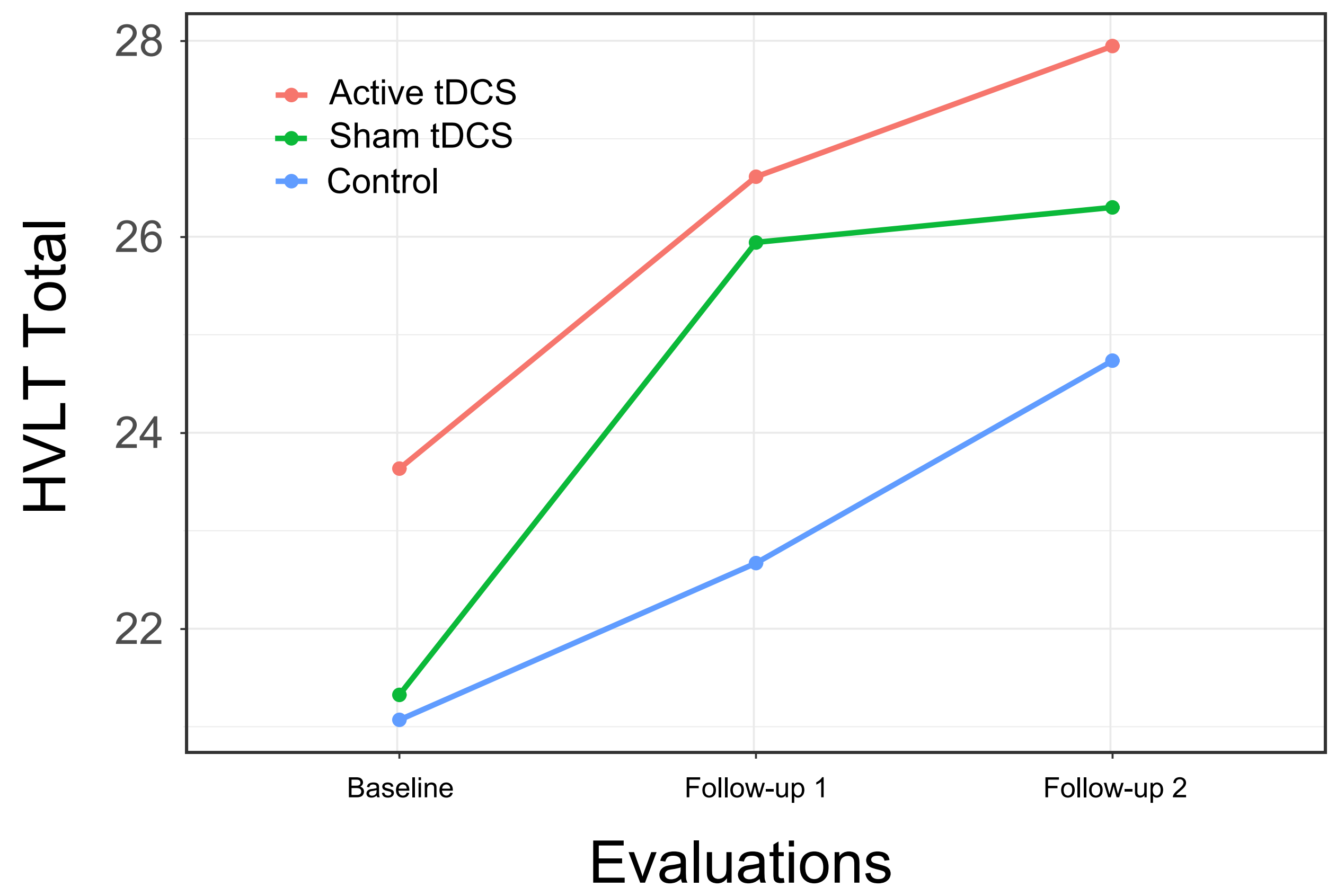




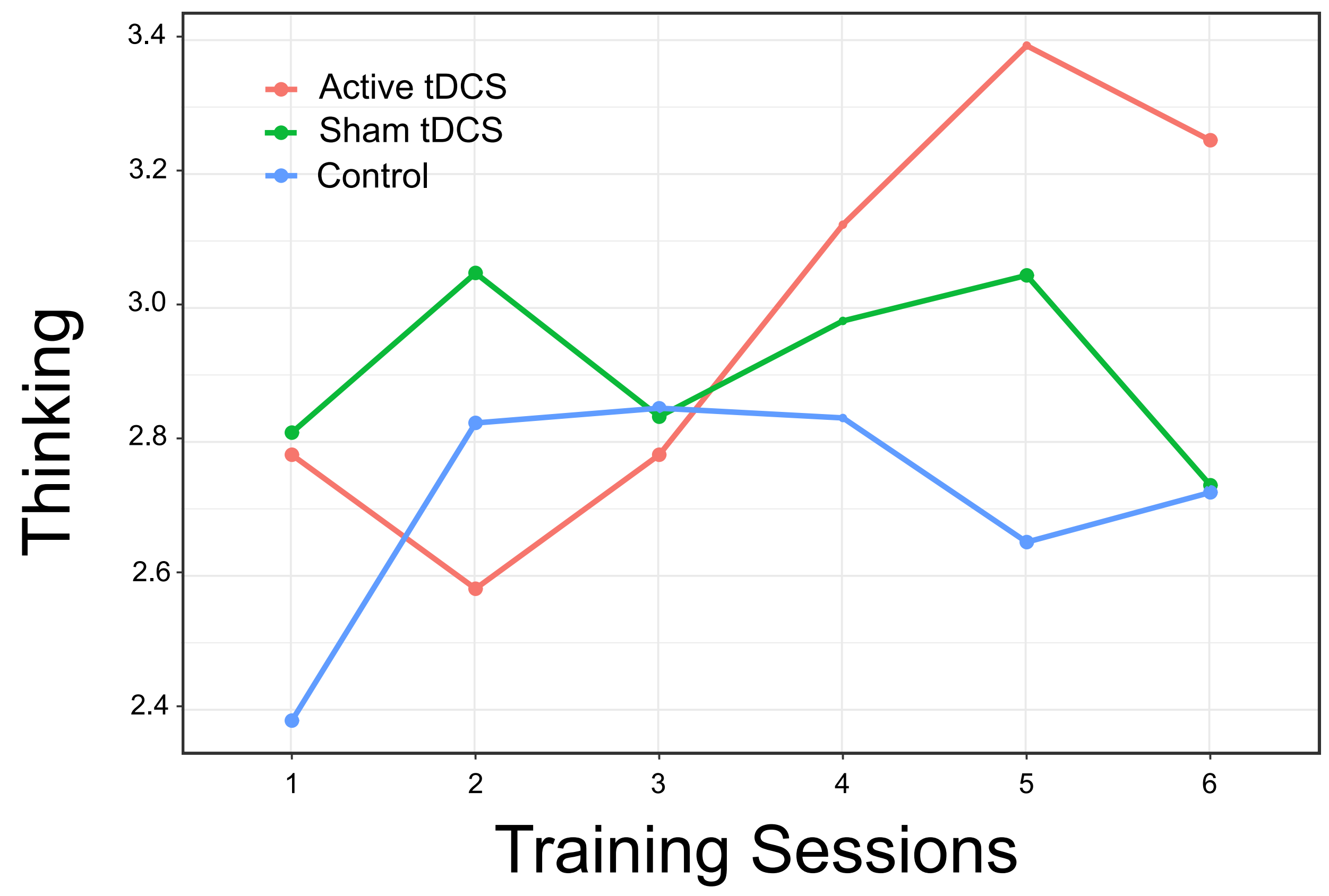

